\title{
Prospective, randomized, controlled trial of polymer cable ties versus standard wire closure of midline sternotomy
}

Silvana F. Marasco, MBBS (Hons), Msurg, PhD, FRACS, ${ }^{\text {a,b }}$ Louise Fuller, B. App Sc, MAPA, Adam Zimmet, MBBS, FRACS, ${ }^{a}$ David McGiffin, MBBS, PhD, FRACS, a,b Michael Seitz, MBBS, ${ }^{a}$ Stephanie Ch'ng, MBBS, ${ }^{\mathrm{a}}$ Shivanand Gangahanumaiah, MBBS, ${ }^{\mathrm{a}}$ and Michael Bailey, PhD, MSc (statistics), BSc (Hons) ${ }^{\mathrm{d}}$

\section{ABSTRACT}

Objective: Midline sternotomy remains the most common access incision for cardiac operations. Traditionally, the sternum is closed with stainless steel wires. Wires are well known to stretch and break, however, leading to pain, nonunion, and potential deep sternal wound infection. We hypothesized that biocompatible plastic cable ties would achieve a more rigid sternal fixation, reducing postoperative pain and analgesia requirements.

Methods: A prospective, randomized study compared the ZIPFIX (De Puy Synthes, West Chester, Pa) sternal closure system $(\mathrm{n}=58)$ with standard stainless steel wires $(n=60)$. Primary outcomes were pain and analgesia requirements in the early postoperative period. Secondary outcome was sternal movement, as assessed by ultrasound at the postoperative follow-up visit.

Results: Groups were well matched in demographic and operative variables. There were no significant differences between groups in postoperative pain, analgesia, or early ventilatory requirements. Patients in the ZIPFIX group had significantly more movement in the sternum and manubrium on ultrasound at 4 weeks.

Conclusions: ZIPFIX sternal cable ties provide reliable closure but no demonstrable benefit in this study in pain or analgesic requirements relative to standard wire closure after median sternotomy. (J Thorac Cardiovasc Surg 2018;156:1589-95)

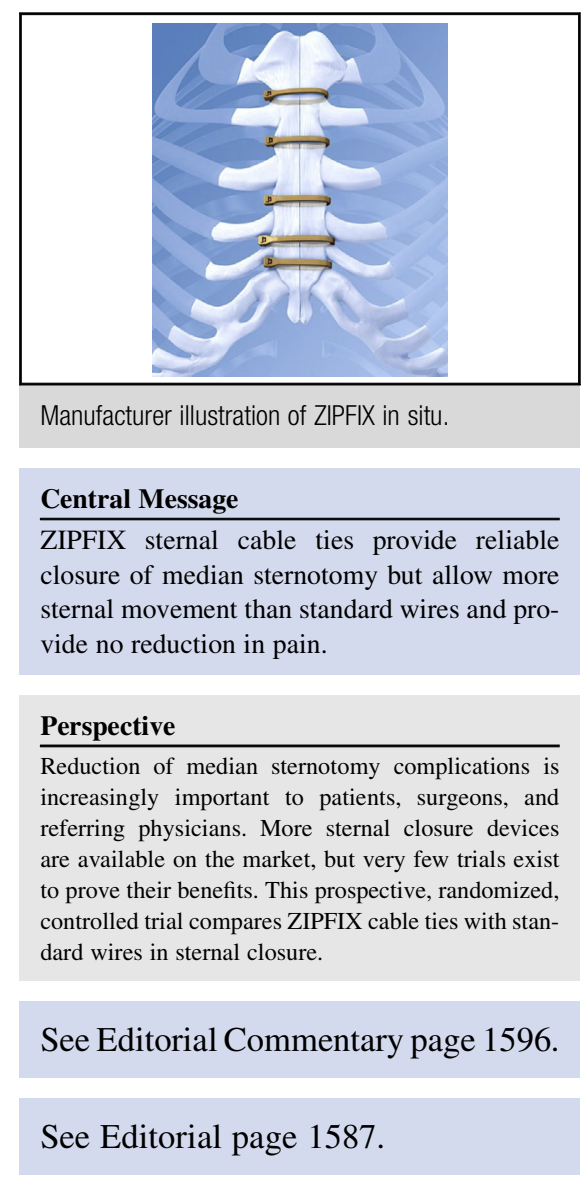

From the ${ }^{\mathrm{a} C J O B}$ Cardiothoracic Surgery Department, The Alfred Hospital, Melbourne, Victoria, Australia; the ${ }^{\mathrm{b}}$ Department of Surgery, The Alfred Hospital, Monash University, Melbourne, Victoria, Australia; the ${ }^{\mathrm{c}}$ Physiotherapy Department, The Alfred Hospital, Melbourne, Victoria, Australia; and the ${ }^{\mathrm{d}}$ Australian and New Zealand Intensive Care Research Centre, Monash University, Melbourne, Victoria, Australia.

This research received no specific grant from any funding agency in the public, commercial, or not-for-profit sectors.

Australian New Zealand Clinical Trials Registry number: ACTRN12615000852550. Alfred Hospital Ethics Committee (EC00315): approved 06 February 2016, Project 385-15.

Received for publication Aug 15, 2017; revisions received April 4, 2018; accepted for publication April 9, 2018; available ahead of print May 16, 2018

Address for reprints: Silvana F. Marasco, MBBS (Hons), MSurg, PhD, FRACS, CJOB Cardiothoracic Department, The Alfred Hospital, Commercial Rd, Prahran 3181, Victoria, Australia (E-mail: s.marasco@alfred.org.au). 0022-5223/\$36.00

Crown Copyright $(\subset) 2018$ Published by Elsevier Inc. on behalf of The American Association for Thoracic Surgery

https://doi.org/10.1016/j.jtcvs.2018.04.025
The midline sternotomy remains the standard access incision for all cardiac surgery. Traditionally, the sternotomy has been closed with stainless steel wires. These wires are vulnerable to stretching and breaking, however, which may occur during tightening of the wires during closure or in the postoperative period. Excessive movement in the midline sternotomy in the postoperative phase is associated with increased pain, infection, and nonunion, the last 2 conditions often requiring repeated surgery to correct the problem. Alternative devices

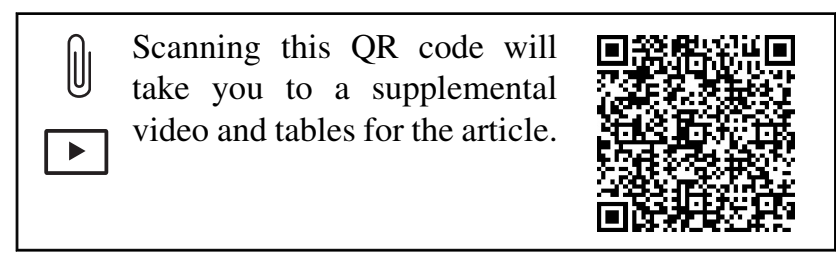




\section{Abbreviations and Acronyms \\ $\mathrm{IQR}=$ interquartile range \\ DSWI $=$ deep sternal wound infection}

to close the sternum are becoming more prevalent and include plates, cables, clips, and bands. ZIPFIX cable ties (De Puy Synthes, West Chester, Pa) are made of polyethyletherketone, a surgically implantable plastic. They have a blunt-tipped needle at one end and a self-locking ratchet at the other end. The cables can be finger tightened initially, and then a tensioning instrument is used to tighten the cables to a preset tension before the instrument cuts the excess cable flush with the ratchet housing. Biomechanical studies have shown that ZIPFIX ties have superior strength and fatigue resistance to stainless steel wires. ${ }^{1}$ Benchtop studies have shown that ZIPFIX ties are less likely to cut through bone than wires because they are $5 \mathrm{~mm}$ wide, making them particularly useful for osteoporotic bone.

The aim of this study was to compare the outcomes of cardiac surgical patients whose median sternotomy was closed with ZIPFIX cable ties with those patients closed with standard stainless steel wires. We hypothesized that ZIPFIX would provide a superior median sternotomy closure with less postoperative pain.

\section{METHODS}

Enrolment for the study took place between February and December 2016. Informed consent was obtained from all enrolled patients. Institutional ethics committee approval was obtained. The trial was registered under Australian New Zealand Clinical Trials Registry (registration number ACTRN12615000852550).

All patients presenting to The Alfred Hospital's cardiothoracic unit for cardiac surgery through a midline sternotomy were eligible for enrolment. Exclusion criteria were redo sternotomy, emergency surgery, cardiac transplant, or ventricular assist device implantation. One hundred twenty patients were enrolled (Figure 1). Randomization was conducted by a computer-generated code with block randomization with a block size of 4 , sealed in an envelope. Patients were randomly allocated the day before surgery to undergo either standard wire closure with 6 to 8 single wires (dependent on patient size) or ZIPFIX closure with a single wire high in the manubrium then 5 ZIPFIX cables. The first ZIPFIX cable was placed around the manubrium, and then 4 parasternal ZIPFIX cables were placed around the body of the sternum. If required, another single parasternal wire was placed inferiorly in the very long sternum. In the standard wire group, wires were placed as single wires, typically 2 in the manubrium passing through bone and at least 4 around the sternum as peristernal wires (Video 1). No patient received topical antibiotics or wax to the sternum.

Standard perioperative care included intravenous prophylactic antibiotics administered at induction ( $2 \mathrm{~g}$ cephazolin) and at 6- hourly intervals for 24 hours. Further antibiotic administration depended on patient condition and intensivist preference. Glucose control was achieved with short-acting insulin infusion, commencing intraoperatively and continuing at least 24 hours, aiming for blood glucose levels of 8 to $11 \mathrm{mmol} / \mathrm{L}$.

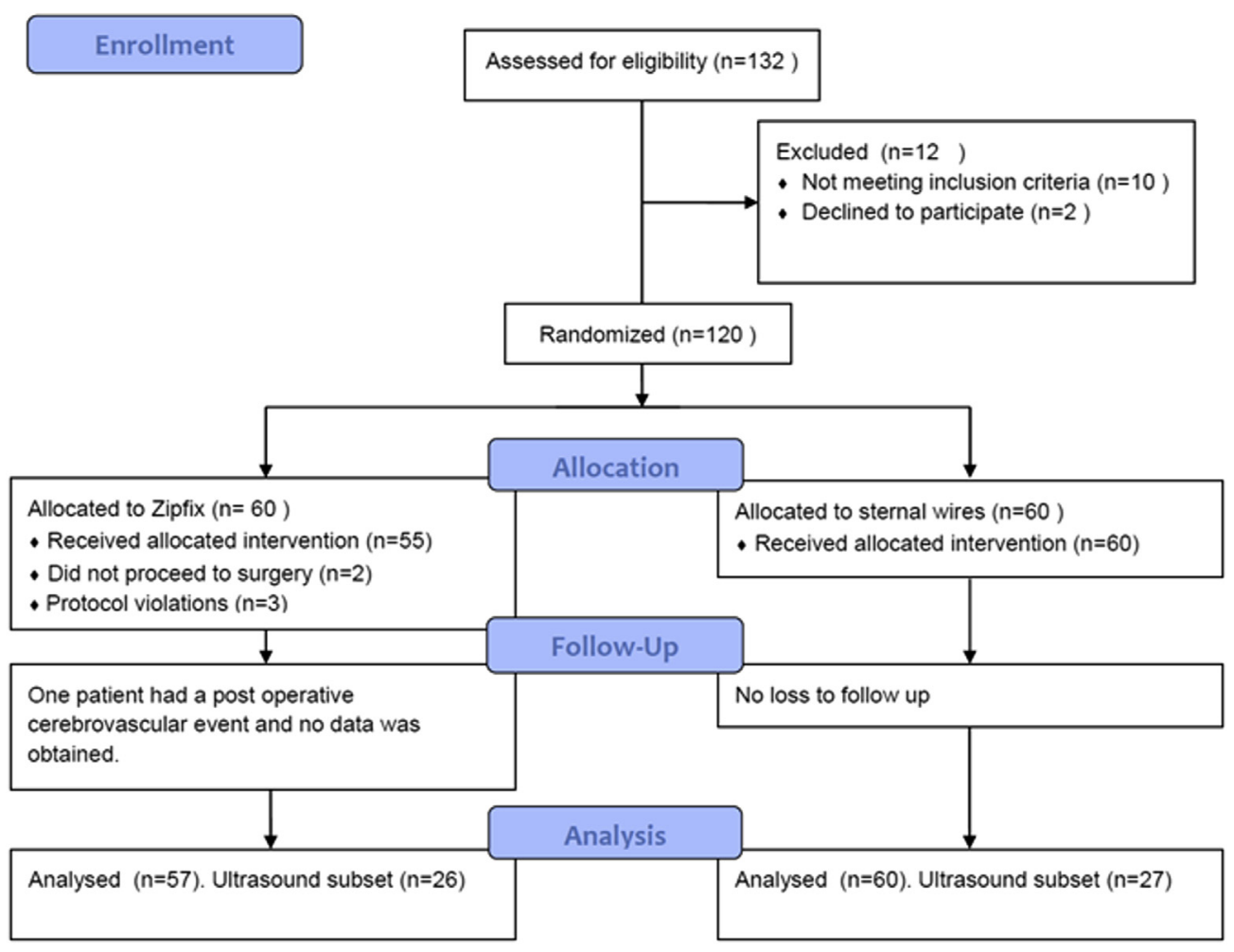

FIGURE 1. Consolidated Standards of Reporting Trials (CONSORT) diagram. 


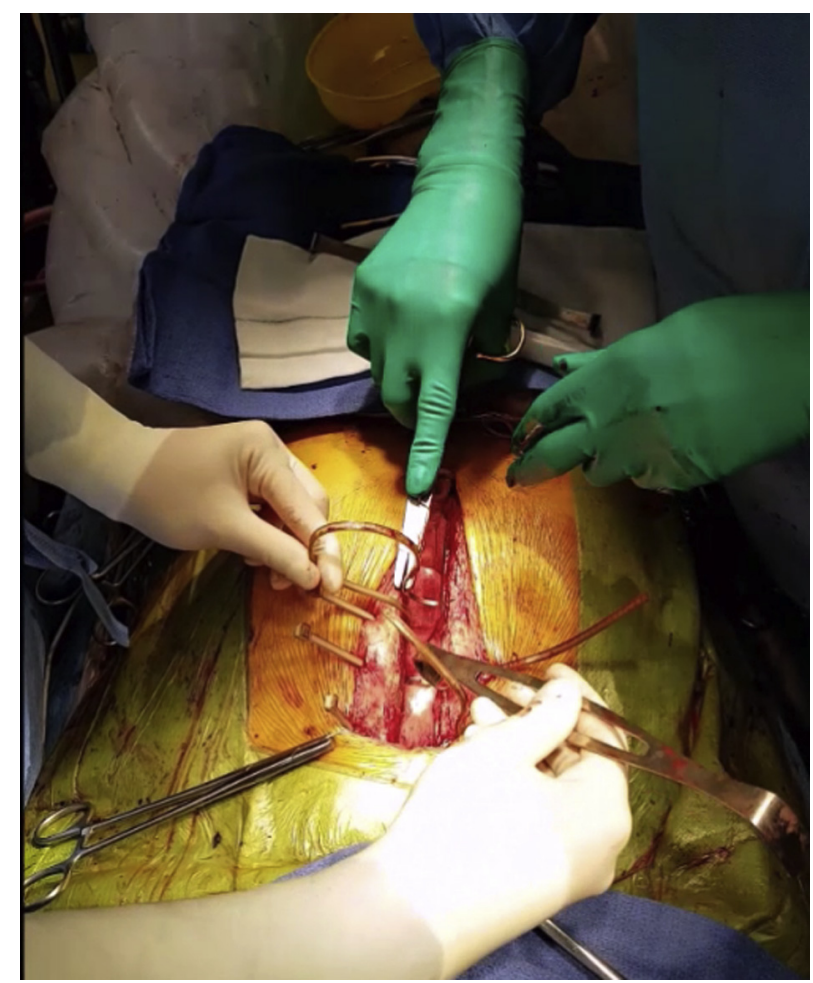

VIDEO 1. Surgical procedure for ZIPFIX (De Puy Synthes, West Chester, Pa) sternal closure system placement. Video available at: https://www. jtcvs.org/article/S0022-5223(18)30998-X/fulltext.

Although the surgeon was not blinded to the treatment arm, the patients, data collectors, and the physiotherapist who performed the ultrasound examinations were blinded to the treatment arm.

The primary end point of the study was postoperative pain, as assessed by an 11-point visual analog scale with anchors at 0 , meaning no pain, and 10 , meaning maximal pain, and by analgesic requirements. ${ }^{2}$ Pain was assessed on days 1 and 3 after extubation, the day of discharge, and at 4 weeks postoperatively.

Secondary outcomes were analgesic requirements post operatively, resternotomy for bleeding, postoperative sternal wound infection and sternal movement which were documented in the post-operative period. Total opioid dose was calculated for 24 hours on day 3 post operatively using the Australian and New Zealand College of Anaesthetists Faculty of Pain Medicine conversion tool. ${ }^{3}$ The standard analgesic regimen for all patients consisted of intravenous morphine as required in the first 24 hours, with regular acetaminophen (INN paracetamol) and long-acting oxycodone commencing once the patient could take oral medications, in general on postoperative day 1 . These were supplemented with short-acting oxycodone, tramadol, or tapentadol as required. Of the 120 patients, a subset who attended The Alfred's postoperative clinic at 4 to 6 weeks underwent ultrasound assessment of sternal movement. Attendance was based on geographic considerations. Sternal malunion was defined as failure of apposition of sternal cortices and failure of callus formation, as noted on computed tomography performed in response to patient reports of ongoing pain or clicking after the 4-week follow-up visit.

Two-dimension ultrasound imaging (SonoSite Turbo; FUJIFILM SonoSite, Inc, Bothell, Wash) was used to measure the distance in millimeters between the cut sternal edges. ${ }^{4,5}$ With the patient supine, ultrasound examination was performed with a linear probe. The patient performed single-arm shoulder flexion and abduction, deep inspiration, and cough while the ultrasound probe was situated over the manubrium and also at midsternal level. Sternal separation was measured with the caliper function (SonoSite Turbo) in both the anteroposterior (sagittal plane) and the lateral (coronal plane) directions.

Sample size estimation was based on postoperative pain according to the visual analog scale. Calculations were performed with data from a previous study analyzing postoperative pain in a cohort of cardiac surgical patients from our institution. ${ }^{6}$ In that study, a reduction of pain by $50 \%$ between groups was found to be clinically significant. With data from that study, a mean pain score of 2.6, and delta value of 1.20 to detect a $50 \%$ reduction in pain with $\alpha$ level of .05 and power of 0.8 , a group size of 54 patients per group was required. Anticipating an attrition rate of $10 \%, 60$ patients per group were enrolled.

\section{Statistical Analysis}

Statistical analysis was performed with SAS version 9.2 (SAS Institute Inc, Cary, NC). All variables were initially assessed for normality. Group comparisons of proportions were made with $\chi^{2}$ tests, or with Fisher exact tests where numbers were small and were reported as numbers. Continuously normally distributed variables were compared with the Student $t$ tests and reported as mean $\pm \mathrm{SD}$, whereas nonnormally distributed data were compared with Wilcoxon rank sum tests and reported as median with interquartile range (IQR). Because pain scores were found to be nonnormally distributed at later time points, analysis of variance was performed on the ranks of the pain scores, resulting in a Friedman nonparametric analysis of variance. The multivariable model was fitted with the main effects of treatment and time and an interaction between treatment and time to determine whether pain scores behaved differently between groups with time with results reported as median with IQR. Post hoc pairwise comparisons at each time point were performed with Bonferroni-corrected comparisons. Additional sensitivity analysis was performed on a modified intention-totreat basis.

Because pain scores were found to be nonnormally distributed at later time points, a unified longitudinal inferential analysis on the ranks of the pain scores was performed with the main effects of treatment and time and an interaction between treatment and time to determine whether pain scores behaved differently between groups with time, with results reported as median with IQR. ${ }^{7}$ Post hoc pairwise comparisons at each time point were performed with Bonferroni-corrected comparisons.

\section{RESULTS}

One hundred twenty patients were consented and enrolled in the study. Two patients did not proceed to surgery and were excluded. Three patients who were enrolled in the ZIPFIX arm of the study had standard wires put in at the choice of the surgeon. Three patients in the ZIPFIX group underwent early reopening for bleeding and had reclosure with wires. Pericostal bleeding where the ZIPFIX device had been passed through the intercostal tissues was the reason in 1 case; the other 2 cases were unrelated to the device. The 6 patients who had conversion to standard wires were analyzed in the ZIPFIX group on an intentionto-treat basis. One patient in the ZIPFIX group had a postoperative cerebrovascular event occur; as a result, no data could be obtained for that patient.

Demographic characteristics of the 2 groups are outlined in Table 1. There were no significant differences between groups. Operative variables are outlined in Table 2. There were no significant differences between groups. Postoperatively, there were no significant differences between groups 
TABLE 1. Patient demographic characteristics

\begin{tabular}{lccc}
\hline \multicolumn{1}{c}{ Variable } & $\begin{array}{c}\text { ZIPFIX } \\
(\mathbf{n = 5 7 ) *}\end{array}$ & $\begin{array}{c}\text { Stainless steel } \\
\text { wires } \\
(\mathbf{n = 6 0}=\mathbf{6 0})\end{array}$ & $\begin{array}{c}\boldsymbol{P} \\
\text { value }\end{array}$ \\
\hline Age $(\mathrm{y}$, mean $\pm \mathrm{SD})$ & $64.9 \pm 11.5$ & $65.6 \pm 11.5$ & .52 \\
Sex $($ male/female) & $46 / 11$ & $46 / 14$ & .59 \\
\hline $\begin{array}{l}\text { Body mass index }\left(\mathrm{kg} / \mathrm{m}^{2},\right. \\
\quad \text { mean } \pm \mathrm{SD})\end{array}$ & $28.8 \pm 4.3$ & $28.7 \pm 5.4$ & .67 \\
Smoking history, n $(\%)$ & $13(22.8)$ & $11(18.3)$ & .59 \\
\hline Underlying lung disease, $\mathrm{n}(\%)$ & $8(14)$ & $10(16.6)$ & .71 \\
Diabetes $(\mathrm{n})$ & 22 & 23 & .98 \\
\hline Osteoporosis $(\mathrm{n})$ & 2 & 1 & .50 \\
\hline
\end{tabular}

$S D$, Standard deviation. *ZIPFIX sternal closure system, De Puy Synthes, West Chester, Pa.

in invasive mechanical ventilation times (ZIPFIX, median 6.5 hours, IQR, 5.1-18.9 hours; wires, median, 6.3 hours; $\mathrm{IQR}, 4.5-9.5 ; P=.066)$.

Although overall postoperative pain levels were lower in the ZIPFIX group, this result was not statistically significant (ZIPFIX, median, 1; IQR, 0-3; vs median, 2; IQR, 0-4; $P=.19)$. There was a significant decrease in pain with time $(P<.0001)$, but there was no evidence to suggest that the decline in pain with time differed between groups (interaction $P=.96$ ) (Table E1). When a per protocol sensitivity analysis was performed, similar results were observed (Table E2). Patients in the ZIPFIX group reported less pain overall, although this difference was not significant (ZIPFIX, median, 0; IQR, 0-3; vs median, 2; IQR, 0-4; $P=.08)$. Although there was a significant overall decline in pain with time $(P<.0001)$, there was no evidence to suggest that the decline in pain with time differed between groups (interaction $P=.66$ ).

Analgesia requirements, as measured by the total opioid dose calculated at day 3 , were found to be $55.6 \pm 49.9 \mathrm{mg} / \mathrm{d}$

TABLE 2. Operative variables

\begin{tabular}{lccc}
\hline \multicolumn{1}{c}{ Variable } & $\begin{array}{c}\text { ZIPFIX } \\
(\mathbf{n = 5 7 ) *}\end{array}$ & $\begin{array}{c}\text { Stainless } \\
\text { steel wires } \\
(\mathbf{n}=\mathbf{6 0})\end{array}$ & $\boldsymbol{P}$ value \\
\hline Operation type & & & \\
$\quad$ AVR & 6 & 2 & .14 \\
CABG & 40 & 48 & .54 \\
CABG plus AVR & 7 & 3 & .19 \\
$\quad$ Other & 4 & 7 & .56 \\
Cardiopulmonary bypass time & $92 \pm 33$ & $94 \pm 46$ & .75 \\
$\quad$ (min, mean \pm SD) & & & \\
Crossclamp time (min, & $71 \pm 29$ & $72 \pm 33$ & .83 \\
$\quad$ mean \pm SD) & & & \\
Single ITA harvest & 43 & 49 & .41 \\
Bilateral ITA harvest & 1 & 2 & .63 \\
\hline
\end{tabular}

$A V R$, Aortic valve replacement; $C A B G$, coronary artery bypass grafting; ITA, internal thoracic artery. *ZIPFIX sternal closure system, De Puy Synthes, West Chester, Pa.
TABLE 3. Patient demographic characteristics of ultrasound analysis subset

\begin{tabular}{|c|c|c|c|}
\hline Variable & $\begin{array}{c}\text { ZIPFIX } \\
(\mathbf{n}=\mathbf{2 9})^{*}\end{array}$ & $\begin{array}{l}\text { Stainless } \\
\text { steel wires } \\
(\mathbf{n}=\mathbf{2 8})\end{array}$ & $P$ value \\
\hline Age $(y$, mean $\pm \mathrm{SD})$ & $64.5 \pm 11.6$ & $64.4 \pm 11.6$ & .97 \\
\hline Sex (male/female) & $24 / 5$ & $17 / 11$ & .06 \\
\hline $\begin{array}{l}\text { Body mass index }\left(\mathrm{kg} / \mathrm{m}^{2},\right. \\
\quad \text { mean } \pm \mathrm{SD})\end{array}$ & $29.9 \pm 4.7$ & $28.2 \pm 5.2$ & .17 \\
\hline Smoking history, n (\%) & $5(17)$ & $8(29)$ & .37 \\
\hline Underlying lung disease, $\mathrm{n}(\%)$ & $4(14)$ & $4(14)$ & .96 \\
\hline Diabetes (n) & 13 & 9 & .44 \\
\hline Osteoporosis (n) & 1 & 1 & .98 \\
\hline \multicolumn{4}{|l|}{ Operation type (n) } \\
\hline AVR & 3 & 3 & .42 \\
\hline CABG & 24 & 22 & .85 \\
\hline CABG plus AVR & 2 & 1 & .6 \\
\hline Other & 0 & 4 & .49 \\
\hline $\begin{array}{l}\text { Cardiopulmonary bypass time } \\
\quad(\text { min, mean } \pm \mathrm{SD})\end{array}$ & $89 \pm 27$ & $83 \pm 32$ & .42 \\
\hline $\begin{array}{l}\text { Crossclamp time (mins, } \\
\text { mean } \pm \mathrm{SD})\end{array}$ & $66 \pm 24$ & $65 \pm 28$ & .85 \\
\hline Single ITA harvest & 24 & 18 & 6 \\
\hline Bilateral ITA harvest & 1 & 2 & .49 \\
\hline
\end{tabular}

for the ZIPFIX cohort versus $53.7 \pm 40.4 \mathrm{mg} / \mathrm{d}$ for the wires cohort $(P=.69)$.

Five patients in the entire cohort had sternal wound infection diagnosed during the follow-up period; 3 of 60 patients $(5 \%)$ in the standard wires group and 2 of 55 patients $(3.6 \%)$ in the ZIPFIX group $(P=.65)$. Of these, 2 infections in the standard wires group and 1 in the ZIPFIX group were deep sternal wound infections (DSWIs) requiring sternal débridement and vacuum dressing. All 3 patients were able to have the sternum closed once sterile, and in all 3 cases, standard wires were used.

Fifty-three patients were followed up at The Alfred Hospital clinic (ZIPFIX, $n=26$; wires, $n=27$ ), and these patients underwent ultrasound examination of the sternum at a median follow-up time of 48 postoperative days (range, 2089 days; Table 3). Results are divided into the manubrium and the body of the sternum and are outlined in Figures 2 and 3. Significantly more movement was noted in the manubrium and the sternum in the ZIPFIX group with all movement types examined. No patient had sternal malunion diagnosed (follow-up censored on April 30, 2017) at a median follow-up of 8 months (range, 4-16 months). 


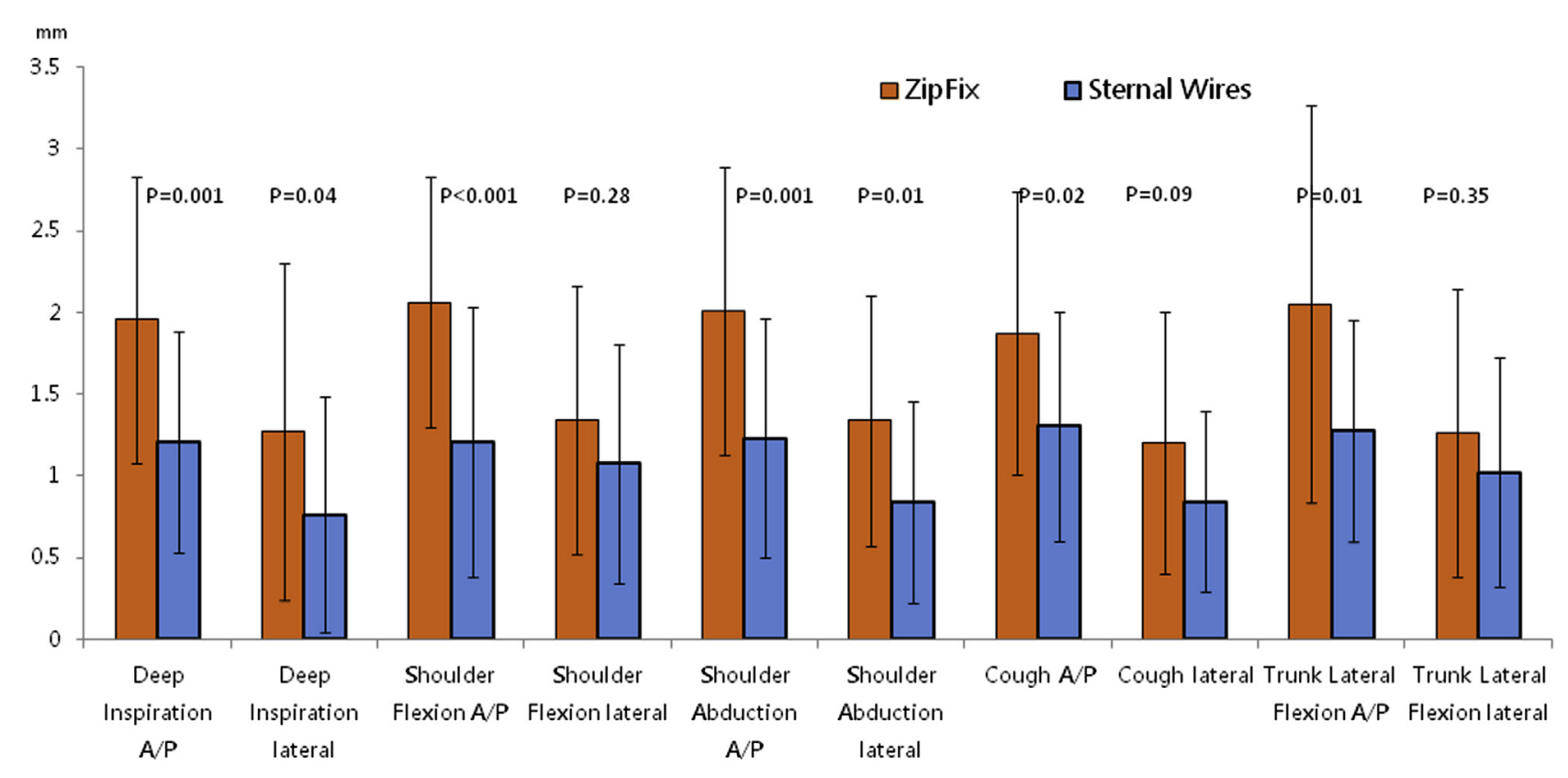

FIGURE 2. Manubrial movement (lateral and anteroposterior $[A / P])$ under various movement conditions, as measured by ultrasound.

\section{DISCUSSION}

Complications of the midline sternotomy access incision remain a significant problem, with the incidence of instability, nonunion, and DSWI reported between $0.5 \%$ and $6.1 \% \cdot{ }^{8-10}$ In high-risk patients, complication rates of $12 \%$ to $20 \%$ have been reported, with an associated mortality of $14 \%$ to $47 \%$, particularly in association with DSWI. ${ }^{9,10}$ Factors that increase the risk of sternal wound complications are well known and include diabetes, smoking, obesity, chronic lung conditions, emergency surgery, prolonged operation, reoperation, and prolonged intensive care stay.

Achieving a stable sternotomy closure is paramount in reducing pain and complications. Stainless steel wires in a variety of configurations have been the mainstay of sternotomy closure for decades, most commonly as simple transverse wire closure or figure-of-eight. The enduring popularity of wires arises from their simplicity and economics. There is a hardware failure rate with stainless steel wires, however, which are well known to stretch, break, and even untwist under lateral forces. ${ }^{11}$ A number of alternative products are now available for sternal closure, including steel bands, titanium plates, stainless steel cables, titanium plates with cables, and nitinol clips. The variety of products now available would indicate that there is a perceived need for a better, more stable, more reliable sternotomy closure method; however, many of these products are expensive and time-consuming to implant. We chose to study ZIPFIX ties because they are simple to use and take no more closure time than standard wires once familiarity with the system has been obtained.
Furthermore, the cost is less than that of many other sternal closure products available. In Australia, a packet of wires costs approximately A $\$ 35$, compared with $\mathrm{A} \$ 700$ for ZIPFIX (which makes the cost of sternal closure in the ZIPFIX patient A $\$ 735$ because a packet of wires needs to be opened). The results of our study were surprising, because we had hypothesized that the ZIPFIX cable ties would give a more rigid sternal closure than wires and thus reduce postoperative pain, analgesic requirements, and sternal movement. This unexpected finding could be explained by the rigidity of the ZIPFIX product. We have noted that the ZIPFIX cable tie forms a circular shape as it encircles the sternum and does not contour to lie completely flat against the outer and inner cortical tables. This inevitably leaves a slight gap between the ZIPFIX cable and the cortical bone anteriorly and posteriorly, which could have allowed sternal movement during our ultrasound examination. The other factor we noted was that the tensioning instrument does not allow the surgeon to tension the ZIPFIX as much as is sometimes required. We often needed to use a heavy needle holder to tighten the cable just one more click through the ratchet. This inability to tighten the ZIPFIX sufficiently with the provided tensioning instrument could help to explain the movement found at the 4- week follow-up visit.

Steel bands have also been used to close median sternotomy incisions and have a similar profile to the cable ties. ${ }^{12,13}$ One of the criticisms of steel bands, however, is that they can be tensioned extremely tightly on the sternum and may potentially interfere with periosteal blood supply. This could be a potential benefit of the 


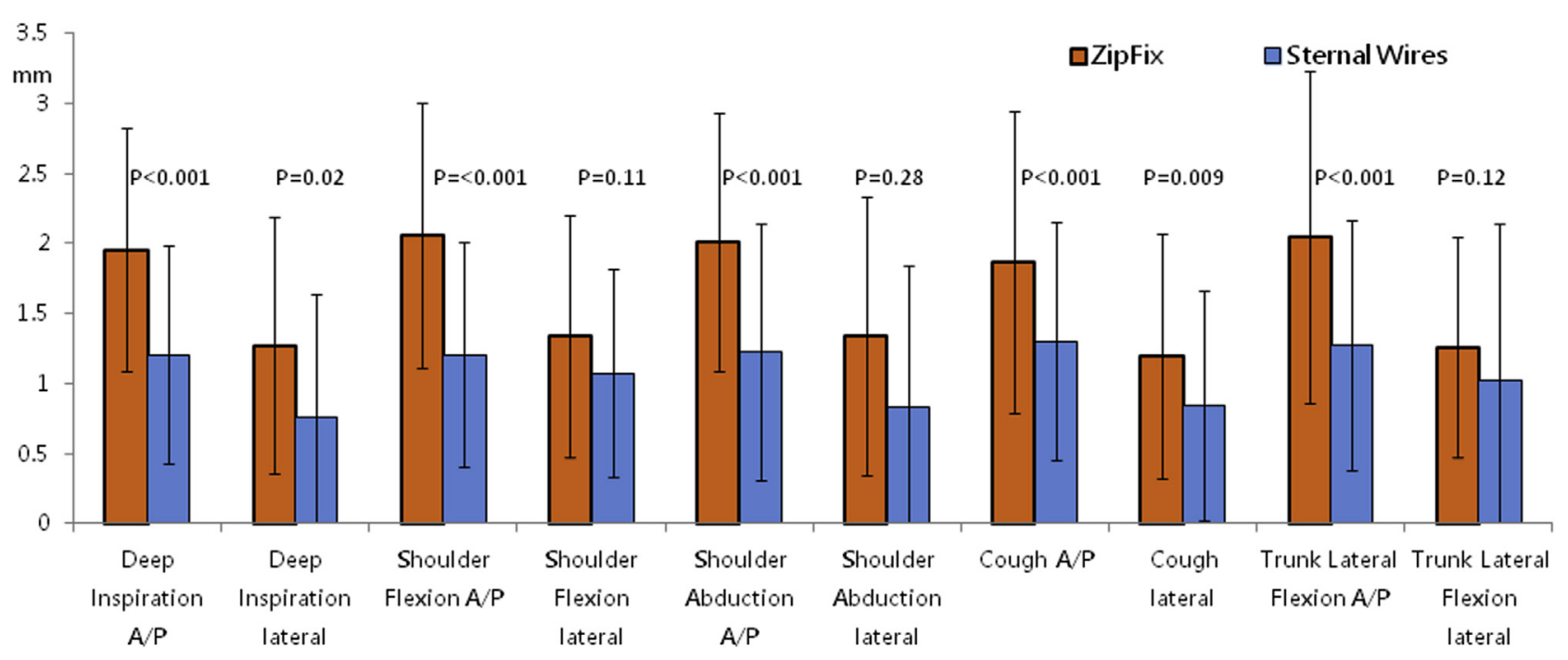

FIGURE 3. Sternal movement (lateral and anteroposterior $[A / P]$ ) under various movement conditions, as measured by ultrasound.

ZIPFIX product, which does not constrict the sternal periosteum in that way.

We did not see any increases in sternal wound infection, foreign-body reaction, or nonunion in the ZIPFIX group, although our study was not powered to identify differences in these outcomes. The ratchet mechanism of the ZIPFIX is quite bulky, and we were concerned that this would cause problems in thin patients. The ratchet does seem to selfbury, however, and sit quite flush in the intercostal spaces.

There are very few published data available on the ZIPFIX system, even though it has been on the market for more than 6 years. Biomechanical testing of the product by Synthes (with 12-mm thick polyurethane foam blocks of $10 \mathrm{lb} / \mathrm{ft}$ ) indicates that 5 ZIPFIX cables used as sternal closure provide significantly superior strength, fatigue resistance, and resistance to cut through than either USP 5 single wires or USP 6 double wires. ${ }^{1}$ A finite element analysis study by Elfström and Grunditz ${ }^{14}$ from Sweden compared ZIPFIX with standard stainless steel wires and with the titanium Sternal Talon (KLS Martin $\mathrm{GmbH}+\mathrm{Co} . \mathrm{KG}$, Freiburg, Germany). In that study, a sternotomy closed with ZIPFIX demonstrated the most displacement, consisting of $0.51 \mathrm{~mm}$ in the midsternum and $2.41 \mathrm{~mm}$ in the lowest part of the sternum. The displacement of the lower sternum was improved by placing a single wire in the lowermost part of the sternum in subsequent analysis. Elfström and Grunditz ${ }^{14}$ commented that much of the displacement occurred with initial stretching of the polyethyletherketone material before inducing any strain.

Two retrospective clinical studies have been published investigating specifically the impact of ZIPFIX closure on sternal wound infection. Melly and colleagues ${ }^{8}$ implanted ZIPFIX in 95 patients after median sternotomy and compared the results with those of 498 patients who had stainless steel wire sternal closure. They found no significant difference between groups in incidence of DSWI or superficial wound infection. The other retrospective study compared 309 patients with stainless steel wire closure and 300 patients with ZIPFIX closure and found a significantly lower DSWI rate in the ZIPFIX group $(0 \%$ vs $2.6 \% ; P=.008) .{ }^{15}$ They also found a lower incidence of sternal dehiscence in the ZIPFIX group, although this difference was not statistically significant $(1 / 300[0.3 \%]$ vs $7 / 309[2.3 \%], P=.069)$. Of note, the groups were not historically comparable (the patients with ZIPFIX closure were operated on later), and there may have been other changes in technique that occurred with time that could have affected the sternal wound infection rate.

Our study is, to our knowledge, the first prospective randomized, controlled trial to investigate the outcomes of patients with ZIPFIX cable tie closure of median sternotomy. The sudden increase and variety of sternal closure systems on the market points to the perceived need for better sternal closure. This need has been identified by both surgeons and insurers. In the United States, DSWI has been deemed to be a "never event" by Medicare, a policy likely to be followed by private insurers in Australia. Achieving a solid sternal closure is paramount in reducing DSWI rates. Despite the proliferation of sternal closure systems on the market, very few prospective randomized, controlled trials have yet been performed. ${ }^{16,17}$ One of the most recent studies, which compared rigid plate fixation with standard wires, also included a cost analysis. ${ }^{17}$ Interestingly, although the rigid plates were a lot more expensive than wires, there were no significant differences between groups in costs at both the index hospitalization and at 6-month follow-up, because of the significantly lower incidence of sternal complications in the rigid plate group. 


\section{Limitations}

This study is limited by its small size and the fact that it is a single-center study. Only 1 surgeon (S.F.M.) had used the ZIPFIX product previously, and so it is possible that there was a learning curve among the other surgeons in the application of the sternal closure system. Not every patient was followed up at The Alfred, and so the ultrasound examination was only applied to a subset of patients who were selected by geographic considerations, making this aspect of the study observational only.

\section{CONCLUSIONS}

In conclusion, the ZIPFIX closure system was found to be easy to use without any hardware failure in this small cohort of patients. Although there appeared to be more movement in the manubrium and body of the sternum in the ZIPFIX group at 4-week follow-up, this finding was not associated with any increased pain or analgesic requirements in that group, either in hospital or at 4 weeks. Larger prospective studies are required to analyze potential benefits of the system in osteoporotic bone and in sternal complications such as nonunion and DSWI.

\section{Conflict of Interest Statement}

S.M. declares the following competing interest: fees received on behalf of DePuy Synthes (device manufacturer) for conference participation (lectures). All other authors have nothing to disclose with regard to commercial support.

\section{References}

1. DePuy Synthes. Sternal ZIPFIX ${ }^{\circledR}$ System. Available at: https://www. depuysynthes.com/hcp/cmf/products/qs/Sternal_ZIPFIX. Accessed May 4, 2017.

2. Bijur PE, Silver W, Gallagher WE. Reliability of the visual analog scale for measurement of acute pain. Acad Emerg Med. 2001;8:1153-7.
3. Australian and New Zealand College of Anaesthetists Faculty of Pain Medicine Opioid dose equivalence. Available at: http://fpm.anzca.edu.au/documents/ opioid-dose-equivalence.pdf. Accessed May 4, 2017.

4. El-Ansary D, Waddington G, Adams R. Relationship between pain and uppe limb movement in patients with chronic sternal instability following cardiac surgery. Physiother Theory Pract. 2007;23:273-80.

5. El-Ansary D, Waddington G, Adams R. Measurement of non-physiological movement in sternal instability by ultrasound. Ann Thorac Surg. 2007;83: 1513-6.

6. Braun LA, Stanguts C, Casanelia L, Spitzer O, Paul E, Vardaxis NJ, et al. Massage therapy for cardiac surgery patients - a randomized trial. J Thorac Cardiovasc Surg. 2012;144:1453-9.e1.

7. Brunner E, Langer F. Nonparametric analysis of ordered categorical data in designs with longitudinal observations and small sample sizes. Biom J. 2000;42: 663-75.

8. Melly L, Gahl B, Meinke R, Rueter F, Matt P, Reuthebuch O, et al. A new cabletie-based sternal closure device: infectious considerations. Interact Cardiovasc Thorac Surg. 2003;17:219-24.

9. Losanoff JE, Jones JW, Richman BW. Primary closure of median sternotomy: techniques and principles. Cardiovasc Surg. 2002;10:102-10.

10. Ridderstolpe L, Gill H, Granfeldt H, Ahlfeldt H, Rutberg H. Superficial and deep sternal wound complications: incidence, risk factors and mortality. Eur J Cardiothorac Surg. 2001;20:1168-75.

11. Casha AR, Gauci M, Yang L, Saleh M, Kay PH, Cooper GJ. Fatigue testing median sternotomy closures. Eur J Cardiothorac Surg. 2001;19:249-53.

12. Franco S, Herrera AM, Atehortúa M, Vélez L, Botero J, Jaramillo JS, et al. Use of steel bands in sternotomy closure: implications in high-risk cardiac surgical population. Interact Cardiovasc Thorac Surg. 2009;8:200-5.

13. Motomatsu Y, Imasaka K, Tayama E, Tomita Y. Midterm results of sternal band closure in open heart surgery and risk analysis of sternal band removal. Artificial Organs. 2016;40:153-8.

14. Elfström A, Grunditz A. Evaluation of sternum closure techniques using finite element analysis. Available at: http://kth.diva-portal.org/smash/get/diva2: 631384/FULLTEXT01.pdf. Accessed July 8, 2017.

15. Stelly MM, Rodning CB, Stelly TC. Reduction in deep sternal wound infection with use of a peristernal cable-tie closure system: a retrospective case series. $J$ Cardiothorac Surg. 2015;10:166-73.

16. Allen KB, Thourani VH, Naka Y, Grubb KJ, Grehan J, Patel N, et al. Randomized, multicenter trial comparing sternotomy closure with rigid plate fixation to wire cerclage. J Thorac Cardiovasc Surg. 2017; 153:888-96.

17. Raman J, Lehmann S, Zehr K, De Guzman BJ, Aklog L, Garrett HE, et al. Sternal closure with rigid plate fixation versus wire closure: a randomized controlled multicenter trial. Ann Thorac Surg. 2012;94:1854-61.

Key Words: sternotomy, cardiac surgery, sternal closure 
TABLE E1. Intention-to-treat analysis of visual analog scale postoperative pain scores

\begin{tabular}{lrcc}
\hline \multicolumn{1}{c}{ Time } & ZIPFIX $^{*}$ & Stainless steel wires & $\boldsymbol{P}$ value \\
\hline Overall & $1(0-3)$ & $2(0-4)$ & .10 \\
Day 1 & $4.5(0-6)$ & $4(3-6)$ & $>.999$ \\
Day 3 & $2(0-3)$ & $2(0-4)$ & $>.999$ \\
Discharge & $0(0-0)$ & $0(0-0)$ & $>.999$ \\
Day 28 & $0(0-2)$ & $1(0-3)$ & $>.999$ \\
\hline
\end{tabular}

Data are median and interquartile range. *ZIPFIX sternal closure system, De Puy Synthes, West Chester, Pa.

TABLE E2. Per protocol analysis of visual analog scale postoperative pain scores

\begin{tabular}{lccc}
\hline \multicolumn{1}{c}{ Time } & ZIPFIX & Stainless steel wires & $\boldsymbol{P}$ value \\
\hline Overall & $0(0-3)$ & $2(0-4)$ & .03 \\
Day 1 & $4.5(0.5-6)$ & $4(3-6)$ & $>.999$ \\
Day 3 & $2(0-4)$ & $2(0-4)$ & .76 \\
Discharge & $0(0-0)$ & $0(0-1)$ & .31 \\
Day 28 & $0(0-2)$ & $1(0-3)$ & .90 \\
\hline Data are median and interquartile range. *ZIPFIX sternal closure system, De Puy \\
Synthes, West Chester, Pa.
\end{tabular}

